\title{
Influences of the East Asian Summer Rainfall on Circumglobal Teleconnection
}

\author{
FULi ZHOU \\ Public Meteorological Service Centre, China Meteorological Administration, Beijing, China
}

RENHE ZHANG

Department of Atmospheric and Oceanic Sciences, Fudan University, and China Meteorological Administration-Fudan University Joint Laboratory of Marine Meteorology, Shanghai, and Innovation Center of Ocean and Atmosphere System, Zhuhai Fudan Innovation Research Institute, Zhuhai, China

\author{
JINPING HAN
}

Chinese Academy of Meteorological Sciences, Beijing, China

(Manuscript received 4 May 2019, in final form 21 February 2020)

\begin{abstract}
In this study, the relationship between circumglobal teleconnection (CGT) and East Asian summer monsoon rainfall was analyzed by data diagnoses and numerical experiments. It is found that the CGT has high spatial and temporal similarities with the teleconnection pattern incurred by the variation of the South Asian high (SAH), which is collaboratively influenced by both Indian and East Asian summer monsoon rainfall. These two teleconnections have similar spatial distributions, and their indices are strongly correlated in temporal variations. Using the partial correlation method, it is revealed that SAH plays a significant role on the propagation of CGT, especially to the east of $90^{\circ} \mathrm{E}$. The numerical experiments indicate that the latent heat release from East Asian summer monsoon rainfall stimulates an upper-tropospheric teleconnection, which shows the same spatial structure with CGT. This study demonstrates that the generation of CGT is not only associated with the Indian summer monsoon rainfall, but also closely with the East Asian summer monsoon rainfall. The CGT is maintained by the latent heat released from the rainfall of both monsoons.
\end{abstract}

\section{Introduction}

The atmospheric circulation system associated with Asian summer monsoon is an important member of atmospheric general circulations in boreal summer. The phase lock relationships of atmospheric circulations among different Asian regions are widely discussed. Previous studies found that the Indian summer rainfall is positively related to that over North China and negatively to that over the Yangtze River valley (Liang 1988; Kripalani and Singh 1993; Kripalani and Kulkarni 1997; Zhang et al. 1999; Zhang 2001; Wei et al. 2015). Indian summer rainfall has an opposite variation to the baiu in southern Japan (Kripalani and Kulkarni 2001; Krishnan and Sugi 2001), whereas it is in phase with the summer rainfall over Southeast Asian countries (Kripalani and Kulkarni 1997). The convection over tropical western

\footnotetext{
Corresponding author: Renhe Zhang, rhzhang@fudan.edu.cn
}

Pacific Ocean near the Philippines also shows significant correlation with the Japanese baiu (Nitta 1987). Several studies reported that the in-phase or out-phase variation of summer rainfall over the Eurasian continent is often accompanied by a midlatitude teleconnection in atmospheric circulation anomalies, which consists of two low-pressure centers over Aral SeaCaspian Sea region and the Japan-Korean peninsula area, respectively, and a high pressure center over Mongolia region (Wang et al. 2001; Krishnan and Sugi 2001). Ding and Wang (2005) proposed a concept of circumglobal teleconnection (CGT) existing in the upper level during boreal summer and propagating along the Asian westerly jet. It shows obvious global characteristics, including six activity centers located in western Europe, eastern Europe, central-western Asia, eastern Asia, the northern Pacific Ocean, and North America, respectively, and the CGT has great influences on Eurasian climate variation. 
The South Asian high (SAH) is a strong and stable anticyclone system over the South Asian highland in the upper-level atmosphere during boreal summer. It is a significant component of both Indian and East Asian summer monsoon systems (Krishnamurti and Bhalme 1976; Yeh and Gao 1979). In the 1960s and 1970s, the east-west oscillation character of SAH was revealed by many studies (Mason and Anderson 1963; Tao and Zhu 1964; Krishnamurti et al. 1973). Besides the zonal movement, the meridional variation of SAH was also discussed in the literature (He et al. 2006; Huang and Qian 2004; Wei et al. 2012). Wei et al. (2015) demonstrated that the interannual variation of SAH is collaboratively influenced by both Indian and East Asian summer monsoon, and manifested its dominant horizontal shift of northwest-southeast movement. Wei et al. (2017) pointed out that when the SAH moves to the southeast, the Asian westerly jet shifts to the southeast, and two cyclones appear over the northwestern Tibetan Plateau and East Asia respectively, while one anticyclone occurs over the southeastern Tibetan Plateau. These cyclone and anticyclone systems can trigger divergence over central Asia and convergence over North China in the high altitudes, resulting in the out-of-phase variation between summer precipitation over North China and central Asia. Considering that both CGT and the SAH are in the upper troposphere over the Eurasian continent and closely related to the Asian summer monsoon precipitation, the question arises as to whether CGT connects with the SAH.

Previous studies proposed a positive feedback mechanism between CGT and Indian monsoon: Indian monsoon precipitation is influenced by CGT through the Rossby waveguide to enhance the atmospheric instability over northwestern India, resulting in anomalous Indian monsoon precipitation; in reverse, extra Indian precipitation releases a quantity of latent heat so that the wave train is capable to propagate downstream (Ding and Wang 2005, 2007; Ding et al. 2011). The East Asian monsoon region is located at the downstream of CGT over Eurasian continent. The East Asian summer monsoon precipitation may trigger heat source variations, which lead to the anomalies of atmospheric circulations ( $\mathrm{Lu}$ and Lin 2009; Wei et al. 2015). Does East Asian summer monsoon precipitation make contribution to the propagation of CGT as well? In fact, SAH is a linkage between the Indian and East Asian rainfall (Wei et al. 2015). When Indian rainfall exhibits significant anomalies, the rainfall over East Asian shows corresponding variations. A question then arises as to what role the SAH will play in the influences of East Asian summer rainfall on CGT propagation.
The remainder of this paper is organized as follows. The dataset, methods, and numerical model used in this study will be introduced in section 2 . Section 3 will discuss the statistical characteristics of CGT and the SAHassociated wave train as well as their possible connection. In section 4 , the possible role played by SAH in CGT will be discussed. In section 5, a climate model will be used to prove the influence of latent heat released from East Asian summer monsoon rainfall on CGT. The conclusions and discussion are given in section 6 .

\section{Data, methods, and model}

The monthly geopotential heights and meridional and zonal winds used in this study are from the reanalysis dataset of National Centers for Environmental Prediction-National Center for Atmospheric Research (NCEP-NCAR) with the spatial resolution of $2.5^{\circ} \times$ $2.5^{\circ}$ for the period of 1948-2013 (Kalnay et al. 1996). The monthly precipitation data for 1979-2013 are from the Global Precipitation Climatology Program (GPCP) (Huffman et al. 1997; Adler et al. 2003), which exhibits great quality over the open ocean (Yin et al. 2004). The summer season in this study is taken to be June, July, and August (JJA).

The CGT index (CGTI) selected in this study is from Ding and Wang (2005) and is defined as the 200-hPa geopotential height anomalies averaged over the key area $35^{\circ}-40^{\circ} \mathrm{N}, 60^{\circ}-70^{\circ} \mathrm{E}$. The SAH index (SAHI), from Wei et al. (2015), is the difference of $200-\mathrm{hPa}$ geopotential height anomalies between the regions $20^{\circ}-27.5^{\circ} \mathrm{N}, 85^{\circ}-115^{\circ} \mathrm{E}$ and $27.5^{\circ}-35^{\circ} \mathrm{N}, 50^{\circ}-80^{\circ} \mathrm{E}$. The SAHI represents the southeast-northwest horizontal shift of the SAH. When the sign of the SAHI is positive, the SAH shifts southeastward; when it is negative, the SAH shifts northwestward. Wei et al. (2015) found that an eastward or westward shift of SAH occurs along with a southward or northward movement, respectively, and proposed that in the interannual time scale the southeast-northwest shift is a dominant feature of the SAH, which is closely connected with the latent heat released from both Indian and East Asian monsoon rainfall.

The ECHAM5 climate model created by German Max Planck Institute for Meteorology (Roeckner et al. 2003) is utilized to analyze the impact of East Asian summer monsoon rainfall on the CGT wave train. This model is a spectral model of T63L31, with horizontal Gaussian grid resolution of $1.875^{\circ}$ (longitude) $\times 1.875^{\circ}$ (latitude) and 31 levels in the vertical direction, and with the top level at $10 \mathrm{hPa}$. Roeckner et al. (2006) comprehensively assessed the performance of ECHAM5 climate model. In our numerical experiments, the climatology from the AMIP2 


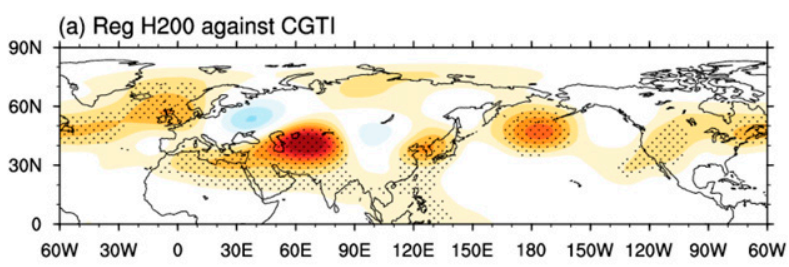

(b) Reg H200 against SAHI

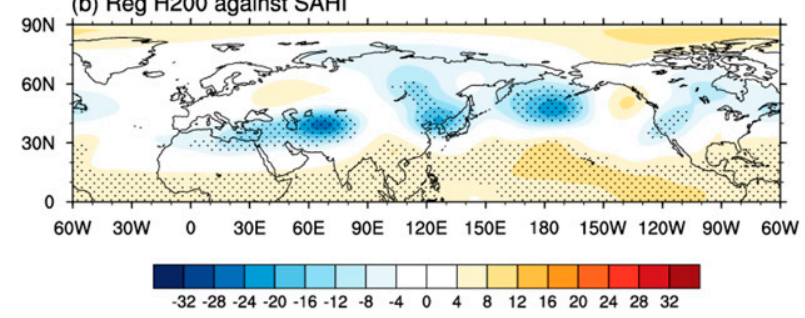

FIG. 1. Regressed JJA 200-hPa geopotential heights against the (a) CGTI and (b) SAHI (shading; gpm) for 1948-2013. Stippling indicates statistical significance exceeding the $95 \%$ confidence level based on the Student's $t$ test.

dataset (Taylor et al. 2000) is taken to be the boundary conditions.

\section{Temporal and spatial characteristics of the wave trains}

Figure 1 shows the regressed 200-hPa geopotential heights against the CGTI (Fig. 1a) and SAHI (Fig. 1b). The anomalous geopotential heights in both Figs. 1a and $1 \mathrm{~b}$ are zonally extended teleconnection wave trains along the Asian jet stream, with significant activity centers located at central-western Asia, eastern Asia, the northern Pacific Ocean, and western North America, respectively. The two wave trains exhibit high similarity over the entire Northern Hemisphere, with a spatial correlation coefficient of -0.73 . If we only focus on the midlatitude region over the Eurasian continent $\left(25^{\circ}-60^{\circ} \mathrm{N}, 20^{\circ} \mathrm{W}-140^{\circ} \mathrm{E}\right)$, the spatial correlation coefficient is -0.76 . Because the SAH index contains the effect from both Indian and East Asian summer monsoon rainfall (Wei et al. 2015), the similarity in spatial structure indicates that the East Asian summer monsoon rainfall may be also important in maintaining CGT. Further, it is also worth noting that the strength of activity centers in each wave train has noticeable differences from its counterpart. The SAH-triggered wave train has significantly weaker centers over its upstream area, the region of the North Atlantic and the United Kingdom. This indicates that SAH may have close association with the wave train downstream.

$\mathrm{Lu}$ et al. (2002) proposed that the meridional winds can better describe the zonally distributed teleconnection wave trains because of their relative independence

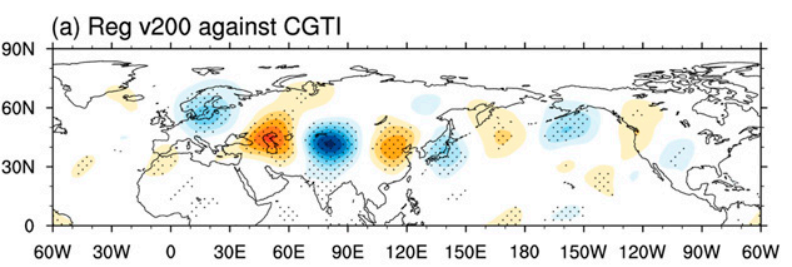

(b) Reg v200 against SAHI

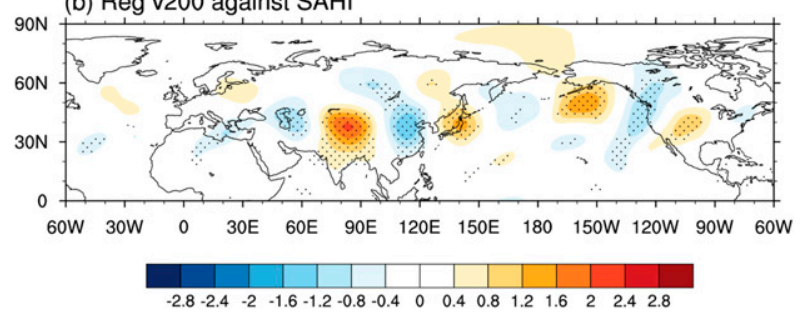

FIG. 2. As in Fig. 1, but for meridional winds $\left(\mathrm{m} \mathrm{s}^{-1}\right)$.

from the meridional movement of westerly jet stream. When 200-hPa meridional winds are regressed against the two indices respectively (Fig. 2), the results manifest more obvious spatial similarity and show a clearer wave train pattern. The spatial correlation coefficient reaches -0.80 over Northern Hemisphere, and even increases to -0.83 when referring to the region over the midlatitude Eurasia $\left(25^{\circ}-60^{\circ} \mathrm{N}, 20^{\circ} \mathrm{W}-140^{\circ} \mathrm{E}\right)$. Similar to the situation of the geopotential height field in Fig. 1, the SAH-related wave train is evidently weaker over the northern Atlantic-United Kingdom region in the upstream, while it is much stronger over eastern North America. The above analyses demonstrate that the SAH-induced wave train has a spatial distribution similar to CGT. To assess their temporal relationship, the correlation coefficient between the time series of these two indices is calculated. The value is -0.7 , which is statistically significant, exceeding the $99.9 \%$ significance level. Therefore, the CGTI-related wave train and the SAH-related wave train have significant correlation with each other on the interannual time scale in both spatial distribution and temporal evolution. However, it should be noted that despite the name of CGT, it is not perfectly circumglobal; rather, its propagation is apparently interrupted over North Atlantic. The wave train signal is missing in both Figs. $2 \mathrm{a}$ and $2 \mathrm{~b}$ over there.

To investigate the role played by SAH in CGT, the method of partial correlation is used to demonstrate the contribution of SAH. When the linear parts of SAH affecting CGT are removed, the regressed 200-hPa meridional winds against CGT stay nearly the same over the Eurasian continent, but change greatly from East Asia to North America (Fig. 3). From $90^{\circ} \mathrm{E}$ to the east, the wave train becomes much weakened, and the downstream activity centers are nearly unrecognizable. According to the above analysis, the variation of SAH 


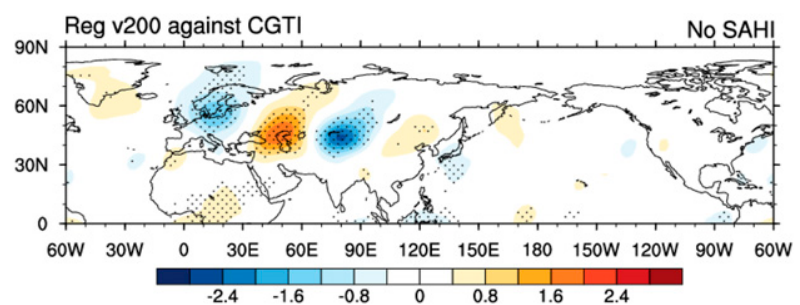

FIG. 3. Regressed JJA 200-hPa meridional winds against the CGTI after removing the influence of the SAH (shading; $\mathrm{m} \mathrm{s}^{-1}$ ) for 1948-2013. Stippling indicates statistical significance exceeding the 95\% confidence levels based on the Student's $t$ test.

may play an important role in the propagation of CGT from upstream to the Pacific Ocean and even to North America. In fact, Fig. 2 has already shown that the SAH is closely related to the wave train downstream to the east of the Eurasian continent.

Ding and Wang (2005) emphasized the prominent role of Indian summer rainfall in the propagation of CGT. Wei et al. (2015) have demonstrated that the horizontal shift of SAH acts as a bond between the Indian and East Asia summer monsoon, which means that the variation of the SAH is influenced not only by Indian monsoon rainfall, but also by East Asian monsoon rainfall. Therefore, in the following we will illustrate the contribution of East Asian summer monsoon rainfall on the propagation of CGT.

\section{Influences of East Asian summer precipitation on CGT}

Figure 4 shows the regressed precipitation against the CGTI and SAHI. Both of the regressed precipitation results indicate that there are three significant precipitation regions, northern India (NIDI; $20^{\circ}-35^{\circ} \mathrm{N}$, $70^{\circ}-85^{\circ} \mathrm{E}$ ), the tropical northwestern Pacific Ocean (TWNP; $12^{\circ}-22^{\circ} \mathrm{N}, 105^{\circ}-140^{\circ} \mathrm{E}$ ), and the subtropical northwestern Pacific Ocean (SWNP; $25^{\circ}-45^{\circ} \mathrm{N}, 125^{\circ}-$ $150^{\circ} \mathrm{E}$ ). In comparing the regressed $200-\mathrm{hPa}$ meridional winds with the averaged regional summer rainfall over each region (Fig. 5), it is found that the global wave train can be reproduced by rainfall over both NIDI (Fig. 5a) and SWNP (Fig. 5c), whereas the regression performed against the regional rainfall over TWNP has not shown an obvious wave train over the Eurasian continent (Fig. 5b). It should be noted that in Fig. 5c, over the Eurasian continent another noticeable wave train can be found over the polar latitudes. The wave train pattern along the polar front jet has been well established, which contributes to the development of the Okhotsk high and therefore affects the climate over Northeast Asia (Nakamura and Fukamachi 2004;

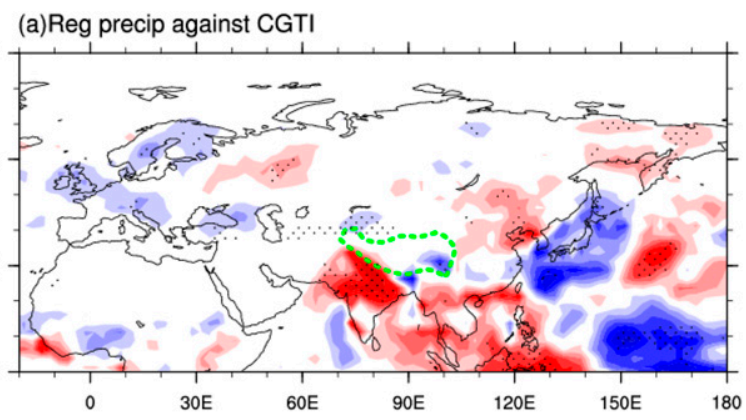

(b)Reg precip against SAHI

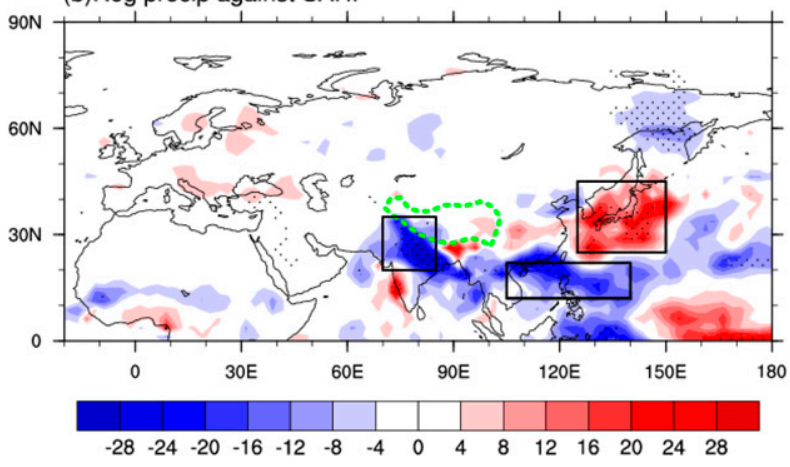

FIG. 4. Regressed JJA GPCP precipitation against the (a) CGTI and (b) SAHI (shading; mm month ${ }^{-1}$ ) for 1979-2013. Stippling indicates statistical significance exceeding the $95 \%$ confidence level based on the Student's $t$ test. The three black-outlined boxes in (b) respectively represent the significant precipitation regions of northern India (NIDI; $20^{\circ}-35^{\circ} \mathrm{N}, 70^{\circ}-85^{\circ} \mathrm{E}$ ), the subtropical northwestern Pacific Ocean (SWNP; $25^{\circ}-45^{\circ} \mathrm{N}, 125^{\circ}-150^{\circ} \mathrm{E}$ ), and the tropical northwestern Pacific Ocean (TWNP; $12^{\circ}-22^{\circ} \mathrm{N}$, $\left.105^{\circ}-140^{\circ} \mathrm{E}\right)$. The green-dashed area indicates the Tibetan Plateau region with elevations exceeding $3000 \mathrm{~m}$.

$\mathrm{Xu}$ et al. 2019). Orsolini et al. (2015) found that the summer rainfall over North China is simultaneously influenced by two wave trains, the polar wave train and the midlatitude wave train. Zhang et al. (2017) showed that the East Asian summer monsoon rainfall is closely related to the polar wave train in addition to the midlatitude Silk Road wave train, which is same as the CGT over the Eurasian continent as demonstrated by Zhou et al. (2019). To some extent, Fig. 5c confirms the conclusions from these studies.

We use the partial correlation method for further analysis. Comparing the regressed 200-hPa meridional winds against the NIDI regional precipitation after removing the contribution of TWNP and SWNP regional precipitation respectively, it is shown that when the influence of TWNP regional precipitation is removed (Fig. 6a), the wave train changes little, which indicates that the tropical northwestern Pacific precipitation has negligible contribution to the wave train. Conversely, when getting rid of the influence of SWNP regional 


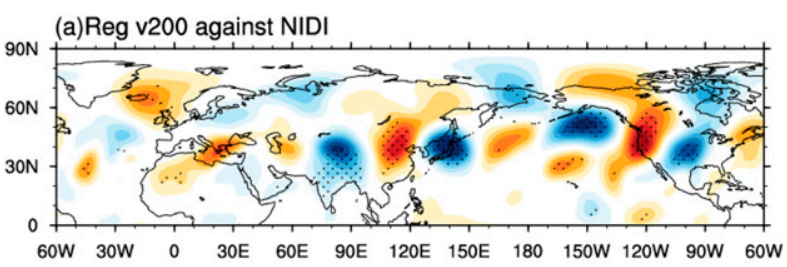

(b)Reg v200 against TWNP

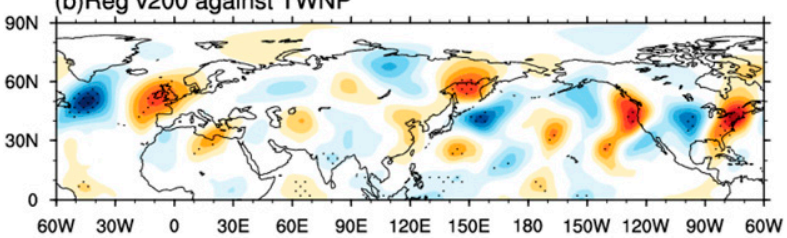

(c)Reg v200 against SWNP

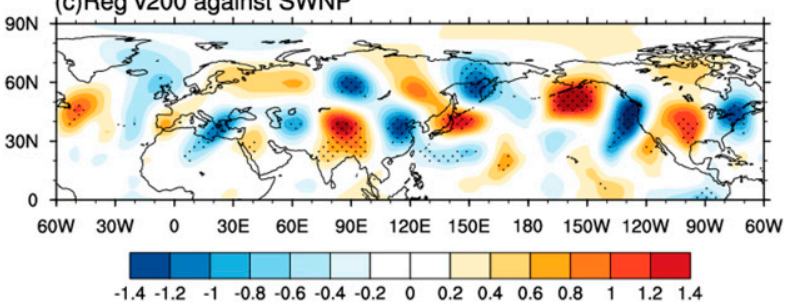

FIG. 5. Regressed JJA 200-hPa meridional winds against averaged precipitation over the (a) NIDI, (b) TWNP, and (c) SWNP regions (shading; $\mathrm{m} \mathrm{s}^{-1}$ ) for 1979-2013. Stippling indicates statistical significance exceeding the $95 \%$ confidence level based on the Student's $t$ test.

precipitation (Fig. 6b), the regressed meridional winds entirely weaken and the wave train structure over Eurasian continent becomes unclear. In addition, after removing the influence of NIDI regional precipitation in the regressed meridional winds against SWNP regional precipitation, the regression pattern still is maintained although the strength of the midlatitude wave train is a little weakened (Fig. 6c). This demonstrates that SWNP makes a great difference to teleconnection wave trains. SWNP is exactly the key area where East Asian summer monsoon precipitation happens. Precipitation has an important effect on wave train propagation through releasing latent heat. Therefore, in the following we will discuss the impact of East Asia (SWNP) summer monsoon rainfall on the CGT wave train.

\section{Numerical experiments}

To demonstrate the role of heat source related to SWNP regional precipitation, we use the residual method to calculate the apparent moisture sink Q2 and the vertical integration of atmospheric apparent moisture sink $\langle\mathrm{Q} 2\rangle$ by using the 6-hourly NCEPNCAR reanalysis data (Yanai et al. 1973). The integrated apparent moisture sink $\langle\mathrm{Q} 2\rangle$ represents the part influenced by water vapor in the atmosphere,
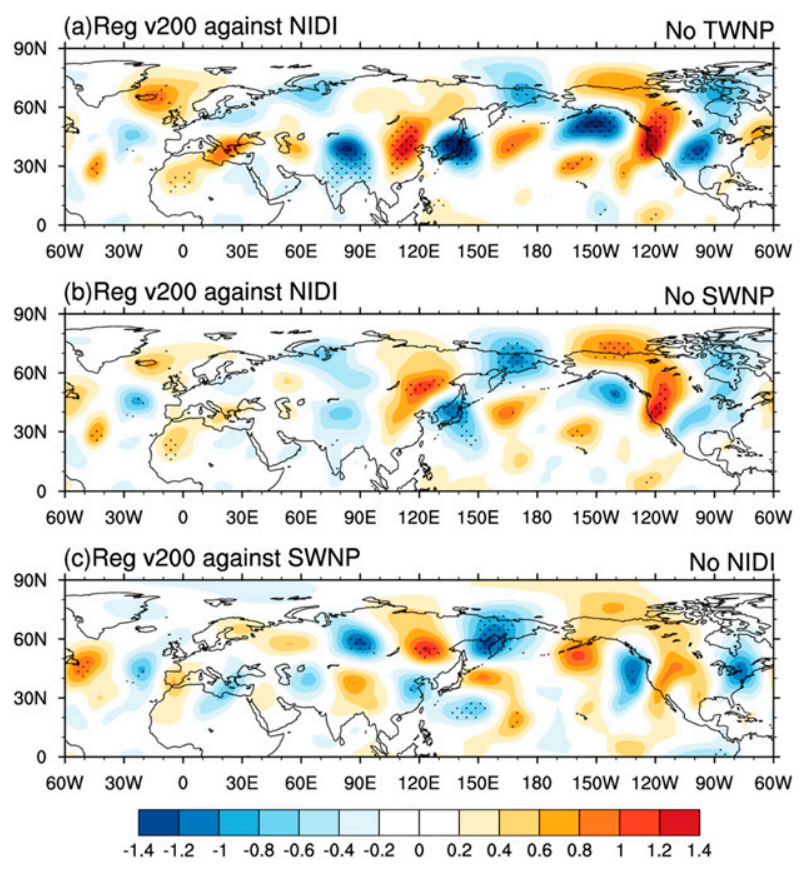

FIG. 6. Regressed JJA 200-hPa meridional winds against NIDI after removing the influence of (a) TWNP and (b) SWNP regional averaged precipitation, and (c) regressed JJA 200-hPa meridional winds against SWNP after removing the influence of NIDI regional averaged precipitation (shading; $\mathrm{m} \mathrm{s}^{-1}$ ) for 1979-2013. Stippling indicates statistical significance exceeding the $95 \%$ confidence level based on the Student's $t$ test.

mainly associated with the released latent heat of condensation. The regressed $\langle\mathrm{Q} 2\rangle$ against the SWNP regional precipitation (Fig. 7a) shows that an anomalous high value band exists over East Asia and northwestern Pacific Ocean. Therefore, we choose the region $22.5^{\circ}-37.5^{\circ} \mathrm{N}, 115^{\circ}-145^{\circ} \mathrm{E}$ (black box in Fig. $7 \mathrm{a}$ ) as the key area for the numerical experiments. The vertical profile of regional averaged Q2 over the key area is shown in Fig. 7b.

According to the vertical profile of Q2 (Fig. 7b), we designed the anomalous heat source experiment (HE experiment) to explore the influence of East Asian summer monsoon rainfall on the CGT wave train. The experiment scheme is as follows: A $1 \mathrm{Kday}^{-1}$ heat source anomaly is settled at $500 \mathrm{hPa}$ over the East China-southern Japan region and adjacent seas centered at $30^{\circ} \mathrm{N}, 130^{\circ} \mathrm{E}$. The vertical profile of the heat source is shown in Fig. 7c, and the horizontal distribution is presented in Fig. 8a. The anomalous horizontal heating decays exponentially outwards from the center.

We performed the control experiment (CTRL) with the ECHAM5 climate model using the climatology from the AMIP2 as boundary conditions. The HE experiment was performed by adding the diabatic heating shown in 

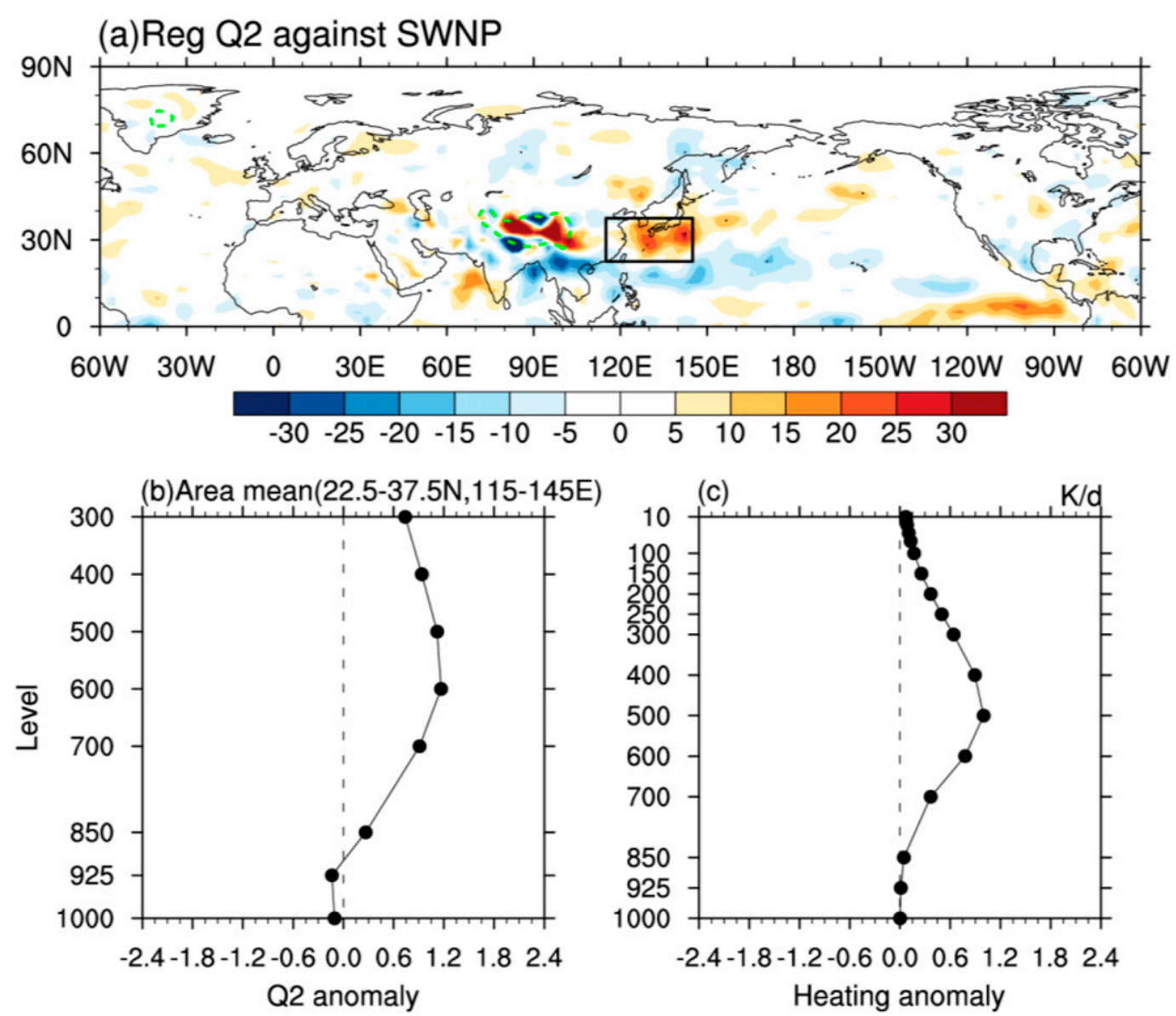

FIG. 7. (a) Regressed JJA integrated apparent moisture sink $\langle Q 2\rangle$ against SWNP regional precipitation (shading; $\mathrm{W} \mathrm{m}^{-2}$ ) for 1979-2013; Stippling indicates statistical significance exceeding the $95 \%$ confidence level based on the Student's $t$ test. (b) The vertical profile of averaged Q2 $\left(\mathrm{K} \mathrm{day}^{-1}\right)$ within the key area [the black-outlined box in (a); $\left.22.5^{\circ}-37.5^{\circ} \mathrm{N}, 115^{\circ}-145^{\circ} \mathrm{E}\right]$. (c) The vertical profile of heat source in the HE experiment $\left(\mathrm{K} \mathrm{day}^{-1}\right)$.

Fig. 7 from 31 May to 31 August in summer (92 days) in the key area over East Asia, and keeping other conditions the same as in the CTRL run. Such integration was conducted for 20 years. The results averaged in 20 summers (JJA) are taken for analysis. The differences between HE and CTRL (shortened as HE-CTRL), obtained by subtracting the CTRL result from the HE one, are used to discuss the role played by the rainfall over SWNP in the CGT wave train.

Figure 8 presents the anomalous atmospheric circulations at $500 \mathrm{hPa}$, where strongest heating exists, in HE-CTRL. It shows several low pressure centers in middle latitudes, including northeastern China, the northern Pacific Ocean, central North America, the northern Atlantic Ocean-United Kingdom region, and the Caspian Sea-Aral Sea region (Fig. 8a). On the corresponding wind field (Fig. 8b), a noticeable global cyclonic and anticyclonic circulation band can be observed, and the strongest cyclonic center lies over the northern Pacific Ocean, namely the downstream region of East Asia.

As shown in Fig. 9, the wave train pattern at $200 \mathrm{hPa}$ is much clearer with more obvious global characteristics and stronger downstream centers along the wave train. On the 200-hPa geopotential heights (Fig. 9a), along the upper-level jet stream axis, there is a zonally extended teleconnection wave train. The positive and negative activity centers are at a distance of about $30^{\circ}$ longitudes. On the 200-hPa wind field (Fig. 9b), the wave train structure is clear. Therefore, in the upper tropospheric circulation, the global teleconnection responding to the anomalous heat source over the East Asia-northwest Pacific region mainly agrees with the CGT pattern in the reanalysis data.

The results of numerical experiments indicate that the latent heat of condensation released from the East Asian summer monsoon rainfall triggers a global teleconnection wave train over its upstream and downstream regions, 

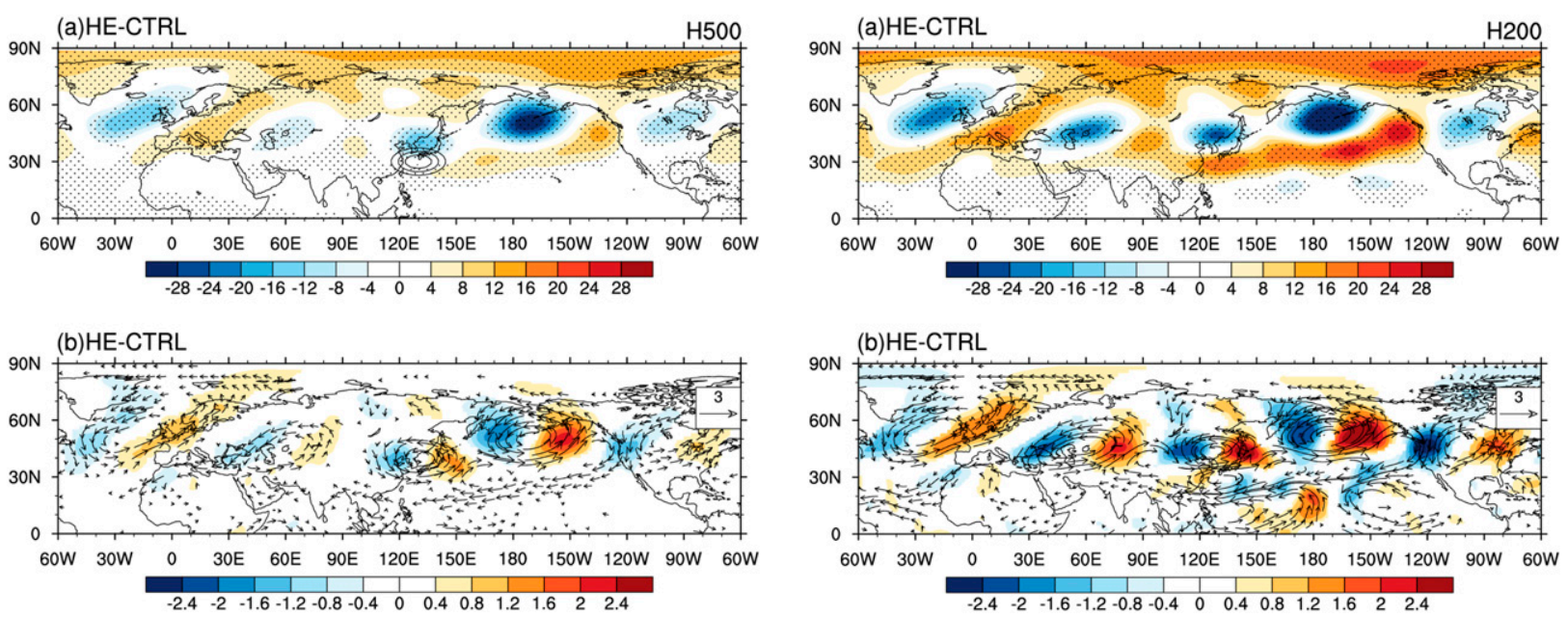

FIG. 8. Composite differences between HE and CTRL in 500-hPa (a) geopotential heights (shading; gpm) and (b) winds (vectors; $\mathrm{m} \mathrm{s}^{-1}$ ). The stippling and contours in (a) are the geopotential heights with statistical significance exceeding the $99 \%$ confidence level based on the Student's $t$ test and the horizontal distribution of heat source at $500 \mathrm{hPa}$ in the $\mathrm{HE}$ experiment $\left(\mathrm{K} \mathrm{day}^{-1}\right)$, respectively. In (b), only the winds with statistical significance exceeding the $99 \%$ confidence level are drawn, and the shadings are the meridional wind strength.

and additionally, the downstream activity centers are much stronger. The obtained wave train accords with the propagation path of the positive phase of CGT, except with the opposite sign. Namely, when more or less monsoon precipitation occurs over East Asia, the anomalous heat source will respectively stimulate the CGT in its negative or positive phase and cause it to propagate downstream. The results of numerical experiments are mainly consistent with those from data diagnoses; that is, the East Asian summer monsoon rainfall is beneficial for the propagation of CGT to the downstream region over North Pacific and North America. However, some differences between observations and model results are also clear. For example, the observed CGT pattern shown in Fig. 2 is apparently interrupted over North Atlantic, but the model results show a straightforward propagation. Such difference may be resulted from different triggers, which may cause different spatial pattern of CGT. Compare to the CGTI-triggered pattern (Fig. 2a), the anomalous centers' related SAH-triggered wave trains (Fig. 2b) are much weaker over the upstream area in the region of the North Atlantic and the United Kingdom, but stronger over its downstream area in eastern North America. Also, the CGTI-related wave train may be mainly confined over the Eurasian continent (Fig. 3). However, the wave train triggered by the heating released from East Asian precipitation has clear circumglobal features, with prominent anomalies over the North Atlantic in both observations (Fig. 6c)

FIG. 9. As in Fig. 8, but for 200-hPa (a) geopotential heights and (b) winds.

and numerical experiments (Fig. 9b). In addition, the simulated response (Fig. 9b) has a phase difference with the observed anomalies (Fig. 2b) by about onequarter wavelength over Eurasia $\left(30^{\circ}-90^{\circ} \mathrm{E}\right)$. These differences may be attributed to the model deficiency.

\section{Conclusions and discussion}

This study analyzed the relationship between CGT and SAH on interannual time scale. It is found that CGT and the SAH-related wave train have strong similarities in spatial distributions, especially to the east of $90^{\circ} \mathrm{E}$ where their structures are nearly the same. In time variation, these two wave train indices are highly correlated with the correlation coefficient of -0.70 . From the statistical method of partial correlation, further analysis found that the removal of SAH-influenced part basically maintains the original spatial structure of CGT over the Eurasian continent, but weakens the wave train to the east of $90^{\circ} \mathrm{E}$, and makes the wave train to the east of $120^{\circ} \mathrm{E}$ inconspicuous. The numerical experiments indicated that the condensation heat release induced by the East Asian summer monsoon rainfall will motivate an anomalous wave train that is out of phase with the positive CGT. In other words, less East Asian summer rainfall strengthens the positive CGT and benefits its downstream propagation. Therefore, the East Asian summer rainfall plays an essential role in the propagation of CGT.

The study of Wei et al. (2015) indicated that the horizontal variation of the SAH is simultaneously influenced by the condensation latent heat released from both Indian and East Asian summer monsoon rainfall. In our partial correlation analysis, when 


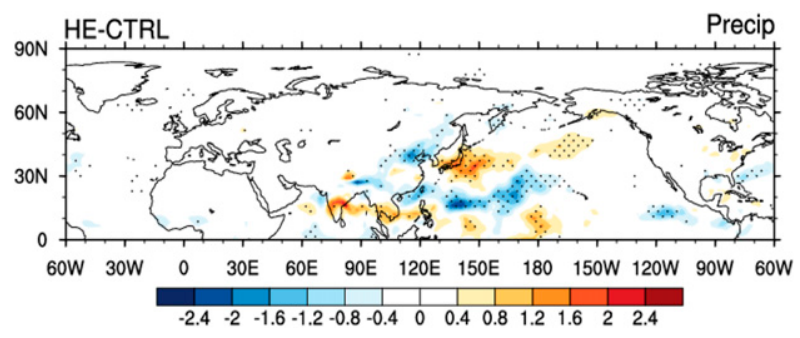

FIG. 10. Composite difference between HE and CTRL in precipitation $\left(\mathrm{mm} \mathrm{day}^{-1}\right)$, with stippling indicating statistical significance exceeding the $99 \%$ confidence level based on the Student's $t$ test.

deleting the influence of the $\mathrm{SAH}$, which virtually deletes the contribution of Indian and East Asian precipitation, the wave train in the downstream recedes obviously. It follows that the maintaining of CGT wave train in its global characteristics is related not only to the Indian monsoon rainfall as pointed out by Ding and Wang (2005), but also to the East Asian summer monsoon rainfall.

It is important to note that apart from the CGT wave train, there is another kind of wave train called the "Silk Road Pattern" (SRP) over the Eurasian continent during boreal summer (Lu et al. 2002; Enomoto et al. 2003). Zhou et al. (2019) documented that over Eurasian continent SRP and CGT are highly consistent with each other. Whether in the spatial distribution or the time variation, they present no significant differences. Therefore, this study did not involve the SRP wave train.

Although the importance of the East Asian summer monsoon rainfall in maintaining CGT is revealed in this study, the East Asian monsoon rainfall variability can be in turn dominantly influenced by dynamical variability in the midlatitudes. For example, considering the significant influence of SRP on East Asian summer climate (e.g., Kosaka et al. 2011), it is reasonable that the East Asian precipitation anomalies can be influenced by SRP, which may feed back to its downstream extension as demonstrated in the present study. As shown in Fig. 10, the simulated precipitation anomalies are abundant over the heat source area. This suggests that the diabatic heating-circulation feedback should be more complicated. The relationship between monsoon rainfall variability in India and East Asia and the SAH variability is likely to be interactive. Their interactions should be an important topic for future investigation.

Acknowledgments. The authors thank three anonymous reviewers for their constructive comments, which helped very much in improving this paper. This study was jointly supported by the National Key Research and
Development Program of China (2016YFA0600602) and the National Natural Science Foundation of China (41790472, 41661144017).

\section{REFERENCES}

Adler, R. F., and Coauthors, 2003: The version-2 Global Precipitation Climatology Project (GPCP) monthly precipitation analysis (1979-present). J. Hydrometeor., 4, 1147-1167, https://doi.org/ 10.1175/1525-7541(2003)004<1147:TVGPCP $>2.0$. CO; 2 .

Ding, Q., and B. Wang, 2005: Circumglobal teleconnection in the Northern Hemisphere summer. J. Climate, 18, 3483-3505, https://doi.org/10.1175/JCLI3473.1.

—, and —, 2007: Intraseasonal teleconnection between the summer Eurasian wave train and the Indian monsoon. J. Climate, 20, 3751-3767, https://doi.org/10.1175/JCLI4221.1.

_ _ - J. M. Wallace, and G. Branstator, 2011: Tropicalextratropical teleconnections in boreal summer: Observed interannual variability. J. Climate, 24, 1878-1896, https:// doi.org/10.1175/2011JCLI3621.1.

Enomoto, T., B. J. Hoskins, and Y. Matsuda, 2003: The formation mechanism of the Bonin high in August. Quart. J. Roy. Meteor. Soc., 129, 157-178, https://doi.org/10.1256/qj.01.211.

He, J., M. Wen, L. Wang, and H. Xu, 2006: Characteristics of the onset of the Asian Summer Monsoon and the importance of Asian-Australian "land bridge." Adv. Atmos. Sci., 23 , 951-963, https://doi.org/10.1007/s00376-006-0951-z.

Huang, Y. Y., and Y. F. Qian, 2004: Relationship between South Asian high and characteristic of precipitation in mid-and lower-reaches of Yangtze River and North China (in Chinese). Plateau Meteor., 23, 68-74.

Huffman, G. J., and Coauthors, 1997: The Global Precipitation Climatology Project (GPCP) combined precipitation dataset. Bull. Amer. Meteor. Soc., 78, 5-20, https://doi.org/10.1175/ 1520-0477(1997)078<0005:TGPCPG > 2.0.CO;2.

Kalnay, E., and Coauthors, 1996: The NCEP/NCAR 40-Year Reanalysis Project. Bull. Amer. Meteor. Soc., 77, 437-472, https://doi.org/10.1175/1520-0477(1996)077<0437:TNYRP> 2.0. $\mathrm{CO} ; 2$

Kosaka, Y., S.-P. Xie, and H. Nakamura, 2011: Dynamics of interannual variability in summer precipitation over East Asia. J. Climate, 24, 5435-5453, https://doi.org/10.1175/ 2011JCLI4099.1.

Kripalani, R. H., and S. V. Singh, 1993: Large scale aspects of IndiaChina summer monsoon rainfall. Adv. Atmos. Sci., 10, 71-84, https://doi.org/10.1007/BF02656955.

_, and A. Kulkarni, 1997: Rainfall variability over southeast Asia-Connections with Indian monsoon and ENSO extremes: New perspective. Int. J. Climatol., 17, 1155-1168, https://doi.org/10.1002/(SICI)1097-0088(199709)17:11<1155: AID-JOC188>3.0.CO;2-B.

$\longrightarrow$, and —, 2001: Monsoon rainfall variations and teleconnections over South and East Asia. Int. J. Climatol., 21, 603-616, https://doi.org/10.1002/joc.625.

Krishnamurti, T. N., and H. N. Bhalme, 1976: Oscillations of a monsoon system. Part I. Observational aspects. J. Atmos. Sci., 33, 1937-1954, https://doi.org/10.1175/1520-0469(1976) 033<1937:OOAMSP > 2.0.CO;2.

- S. M. Daggupaty, J. Fein, M. Kanamitsu, and J. D. Lee, 1973: Tibetan high and upper tropospheric tropical circulations during northern summer. Bull. Amer. Meteor. Soc., 54, 1234-1250, https://doi.org/10.1175/1520-0477-54.12.1234. 
Krishnan, R., and M. Sugi, 2001: Baiu rainfall variability and associated monsoon teleconnections. J. Meteor. Soc. Japan, 79, 851-860, https://doi.org/10.2151/jmsj.79.851.

Liang, P.-D., 1988: Indian summer monsoon and rainfall in North China in summer (in Chinese). Acta Meteor. Sin., 46, 75-81.

Lu, R., and Z. Lin, 2009: Role of subtropical precipitation anomalies in maintaining the summertime meridional teleconnection over the western North Pacific and East Asia. J. Climate, 22, 2058-2072, https://doi.org/10.1175/2008JCLI2444.1.

— J. H. Oh, and B. J. Kim, 2002: A teleconnection pattern in upper-level meridional wind over the North African and Eurasian continent in summer. Tellus, 54A, 44-55, https:// doi.org/10.3402/tellusa.v54i1.12122.

Mason, R. B., and C. E. Anderson, 1963: The development and decay of the 100-mb summertime anticyclone over southern Asia. Mon. Wea. Rev., 91, 3-12, https://doi.org/10.1175/ 1520-0493(1963)091<0003:TDADOT>2.3.CO;2.

Nakamura, H., and T. Fukamachi, 2004: Evolution and dynamics of summertime blocking over the Far East and the associated surface Okhotsk high. Quart. J. Roy. Meteor. Soc., 130, 1213-1233, https://doi.org/10.1256/qj.03.101.

Nitta, T., 1987: Convective activities in the tropical western Pacific and their impact on the Northern Hemisphere summer circulation. J. Meteor. Soc. Japan, 65, 373-390, https://doi.org/ 10.2151/jmsj1965.65.3_373.

Orsolini, Y. J., L. Zhang, D. H. W. Peters, K. Fraedrich, X. Zhu, A. Schneidereit, and B. van den Hurk, 2015: Extreme precipitation events over north China in August 2010 and their link to eastward-propagating wave-trains across Eurasia: Observations and monthly forecasting. Quart. J. Roy. Meteor. Soc., 141, 3097-3105, https://doi.org/10.1002/qj.2594.

Roeckner, E., and Coauthors, 2003: The atmospheric general circulation model ECHAM 5. Part I: Model description. MaxPlanck-Institut für Meteorologie Rep. 349, 127 pp.

- , and Coauthors, 2006: Sensitivity of simulated climate to horizontal and vertical resolution in the ECHAM5 atmosphere model. J. Climate, 19, 3771-3791, https://doi.org/ 10.1175/JCLI3824.1.

Tao, S. Y., and F. K. Zhu, 1964: The $100 \mathrm{mb}$ flow patterns in southern Asia in summer and its relation to the advance and retreat of the west Pacific subtropical anticyclone over the Far East (in Chinese). Acta Meteor. Sin., 34, 385-396.

Taylor, K. E., D. Williamson, and F. Zwiers, 2000: The sea surface temperature and sea-ice concentration boundary conditions for AMIP II simulations. Lawrence Livermore National Laboratory Program for Climate Model Diagnosis and Intercomparison Tech. Rep. 60, UCRL-MI-125597, 28 pp.
Wang, B., R.-G. Wu, and K.-M. Lau, 2001: Interannual variability of the Asian summer monsoon: Contrasts between the Indian and the western North Pacific-East Asian monsoons. J. Climate, 14, 4073-4090, https://doi.org/10.1175/ 1520-0442(2001)014<4073:IVOTAS >2.0.CO;2.

Wei, W., R. Zhang, and M. Wen, 2012: Meridional variation of South Asian high and its relationship with the summer precipitation over China (in Chinese). J. Appl. Meteor. Sci., 23, 650-659.

,,--- B. J. Kim, and J. C. Nam, 2015: Interannual variation of the South Asian high and its relation with Indian and East Asian summer monsoon rainfall. J. Climate, 28, 2623-2634, https://doi.org/10.1175/JCLI-D-14-00454.1.

,,--- , and S. Yang, 2017: Relationship between the Asian westerly jet stream and summer rainfall over central Asia and North China: Roles of the Indian monsoon and the South Asian high. J. Climate, 30, 537-552, https://doi.org/ 10.1175/JCLI-D-15-0814.1.

Xu, P., L. Wang, and W. Chen, 2019: The British-Baikal corridor: A teleconnection pattern along the summertime polar front jet over Eurasia. J. Climate, 32, 877-896, https://doi.org/10.1175/ JCLI-D-18-0343.1.

Yanai, M., E. Steven, and J. H. Chu, 1973: Determination of bulk properties of tropical cloud clusters from large-scale heat and moisture budgets. J. Atmos. Sci., 30, 611-627, https://doi.org/ 10.1175/1520-0469(1973)030<0611:DOBPOT >2.0.CO;2.

Yeh, D., and Y. Gao, 1979: Meteorology of the Tibetan Plateau (in Chinese). Science Publication Agency, 278 pp.

Yin, X., A. Gruber, and P. Arkin, 2004: Comparison of the GPCP and CMAP merged gauge-satellite monthly precipitation products for the period 1979-2001. J. Hydrometeor., 5, 1207-1222, https:// doi.org/10.1175/JHM-392.1.

Zhang, R. H., 2001: Relations of water vapor transport from Indian monsoon with that over East Asia and the summer rainfall in China. Adv. Atmos. Sci., 18, 1005-1017, https:// doi.org/10.1007/BF03403519.

—, A. Sumi, and M. Kimoto, 1999: A diagnostic study of the impact of El Niño on the precipitation in China. Adv. Atmos. Sci., 16, 229-241, https://doi.org/10.1007/BF02973084.

Zhang, R. N., R. H. Zhang, and Z. Zuo, 2017: Impact of Eurasian spring snow decrement on East Asian summer precipitation. J. Climate, 30, 3421-3437, https://doi.org/ 10.1175/JCLI-D-16-0214.1.

Zhou, F., R. Zhang, and J. Han, 2019: Relationship between the circumglobal teleconnection and Silk Road Pattern over Eurasian continent. Sci. Bull., 64, 374-376, https://doi.org/ 10.1016/j.scib.2019.02.014. 